\title{
Tuberculosis treatment outcomes: a fifteen- year retrospective study in Jos-North and Mangu, Plateau State, North - Central Nigeria
}

Comfort Nanbam Sariem ${ }^{1 *}$ (D, Patricia Odumosu², Maxwell Patrick Dapar ${ }^{1}$, Jonah Musa ${ }^{3}$, Luka Ibrahim ${ }^{4}$ and John Aguiyi ${ }^{5}$

\begin{abstract}
Background: Globally, tuberculosis (TB) is the leading cause of death from a single infectious agent. Adherence to TB therapy is an important factor in treatment outcomes, which is a critical indicator for evaluating TB treatment programs. This study assessed TB treatment outcomes using a fifteen-year record of tuberculosis patients who received treatment in Jos-North and Mangu Local Government Areas of Plateau State, North-Central Nigeria.

Methods: The retrospective facility based study was done in five TB treatment centers which account for more than half of data for tuberculosis patients in Plateau State. Data were collected from 10,156 TB patient's health records between 2001 and 2015. Treatment outcomes were categorized as successful (cured, treatment completed) or unsuccessful (non-adherent, treatment failure or death). A descriptive analysis was done to assess the factors associated with treatment outcomes. Relevant bivariate and multivariate logistic regression were done. All statistical analyses were performed on Stata version 11, College station, Texas, USA.

Results: During the study period, 58.1\% (5904/10156) of the TB patients who received treatment were males. The Mean age \pm SD was $35.5 \pm 15.5$ years. The overall treatment success rate was $67.4 \%$; non-adherence/defaulting rate was $18.5 \%$, with majority of patients defaulting at the end of intensive phase of treatment. The sputum conversion rate was $72.8 \%$ and mortality rate was 7.5\%. A decrease in successful treatment outcomes rate from $83.8 \%$ in 2001 to $64.4 \%$ in 2015 was observed. The factors associated with treatment success were gender, age, year of enrollment, and HIV status. Extrapulmonary TB was less likely associated with treatment success (AOR:95\% Cl- 0.72:0.61-0.84, $p<0.001$ ).

Conclusion: With the decrease in treatment success rates, underlying reasons for medication non-adherence and treatment failure should be resolved through adherence counseling involving the patient and treatment supporters, with education on voluntary counseling and testing for HIV among TB patients.
\end{abstract}

Keywords: Tuberculosis, Treatment outcomes, Retrospective study, Plateau State, Nigeria

\footnotetext{
* Correspondence: sariemcn@gmail.com

'Department of Clinical Pharmacy and Pharmacy Practice, Faculty of Pharmaceutical Sciences, University of Jos, Plateau State, Jos, Nigeria

Full list of author information is available at the end of the article
}

(c) The Author(s). 2020 Open Access This article is licensed under a Creative Commons Attribution 4.0 International License, which permits use, sharing, adaptation, distribution and reproduction in any medium or format, as long as you give appropriate credit to the original author(s) and the source, provide a link to the Creative Commons licence, and indicate if changes were made. The images or other third party material in this article are included in the article's Creative Commons licence, unless indicated otherwise in a credit line to the material. If material is not included in the article's Creative Commons licence and your intended use is not permitted by statutory regulation or exceeds the permitted use, you will need to obtain permission directly from the copyright holder. To view a copy of this licence, visit http://creativecommons.org/licenses/by/4.0/ The Creative Commons Public Domain Dedication waiver (http://creativecommons.org/publicdomain/zero/1.0/) applies to the data made available in this article, unless otherwise stated in a credit line to the data. 


\section{Background}

Tuberculosis (TB) is a bacterial infection caused by Mycobacterium tuberculosis. It is a major global public health concern being the tenth leading cause of death worldwide, and the leading cause of death from a single infectious agent since 2011, ahead of the Human Immunodeficiency Virus (HIV) disease [1]. Globally, 10 million people $(0.13 \%)$ were estimated to have fallen ill with TB in 2017; equivalent to 132 cases per 100,000 population, with $9 \%$ of the 10 million people being HIVpositive. Death toll globally from TB disease was 1.3 million, with an additional 300,000 deaths from TB among HIV positive patients in 2017. In Nigeria, TB mortality, including HIV associated TB death was 155, 000 in 2017; the second highest reported mortality globally, after India [2]. The global treatment success rate was $82 \%$ among all new TB cases [1]. TB treatment saved 53 million lives globally (including HIV positive TB patients) and 11 million lives were saved in Africa. Nigeria recorded a treatment success of $86 \%$ in 2017. However, Nigeria was 6th among the high TB burden countries after India, China, Indonesia, Philippines and Pakistan [1]. There are 30 high TB burden countries (HBCs) which collectively have about $87 \%$ of the world's TB cases. Nigeria is among the 14 countries with overlap of high burden of TB, TB/HIV and multidrug resistantTB (MDR-TB). HBC is defined as around 100 or more cases per 100,000 population [3]. The total TB incidence rate in Nigeria was $219 / 100,000$ population (population of 191 million people), out of which of $14 \%$ were HIV positive [1].

In Plateau state Nigeria, the Directly Observed Therapy (DOT), which is the WHO recommended treatment strategy for TB started in 2001 with five centers and expanded to 290 centers in 2019. A summary of the treatment success rate for Plateau state from 2001 to 2010 was $72.7 \%$, defaulting rate was $14.1 \%$ and mortality rate was $8.0 \%$ [4].

Mycobacterium tuberculosis is an intracellular microorganism that replicates very slowly, therefore prolonged multi-drug treatment regimen (6 months) is the recommended treatment strategy implemented through the Directly Observed Therapy (DOT) [5]. Because of this treatment regimen, medication non-adherence remains a potential challenge. Prevention of new TB infections and their progression to $(\mathrm{TB})$ disease is crucial in reducing the burden of disease and death caused by TB, and in achieving the End TB Strategy targets set for 2030 and 2035, which is linked with the target of the Sustainable Development Goal-SDG; to reduce the number of TB deaths by $90 \%$ by 2030 , cut new cases by $80 \%$ between 2015 and 2030, and to ensure no family is burdened with catastrophic cost due to TB [6]. Current health interventions for TB prevention include: treatment of latent TB infection (LTBI), with particular attention to children aged less than five years and HIV positive TB patients, prevention of transmission of $M$. TB through infection control especially among health workers; and vaccination of children with the Bacille Calmette-Guérin (BCG) vaccine [1].

Efforts have been made to identify factors influencing medication adherence [7-13], from which interventions [13-17] have been developed to improve adherence. This is because adherence has been shown to have profound effect on other treatment outcomes [18]. Indeed, non-adherence and mortality have been shown to account for 64 and $32 \%$ poor/unsucuccessful treatment outcomes respectively [19]. A study observed that most intervention studies targetted only adherence, but improving adherence would be more valuable if it improved clinical/treatment outcomes of the patient [20]. This study therefore focused on understanding the factors associated with treatment outcomes for TB patients, since treatment outcomes are major indicators for evaluating TB treatment programs.

In Nigeria, studies have reported trends in tuberculosis treatment outcomes for the country [1], and for different states within the country $[21,22]$. However assessment of treatment outcomes in individual DOT TB facilities is lacking [23]. This will enable facility-specific interventions to be implemented. Therefore, we sought to assess the factors associated with TB treatment outcomes, with more focus on the effect HIV has on TB treatment outcomes in five DOT facilities in Jos-North and Mangu Local Government Areas of Plateau state, North-Central Nigeria through a 15 - year retrospective study.

\section{Methods}

\section{Study design and setting}

A retrospective facility-based study of TB patient's records from January 2001 to December 2015 was done in five DOT TB treatment facilities in Jos-North and Mangu Local Government Areas of Plateau State, North-Central Nigeria, in order to assess tuberculosis treatment outcomes. Plateau State has a land mass area of $26,899 \mathrm{~km}^{2}$ with a population of $3,206,531$ people [24]. The TB facilities were preselected because they account for more than $50 \%$ of all TB cases in Plateau State, and had the needed health records of TB patients since the onset of the DOT programme in 2001. Demographic and patient data collected by the health workers at the facilities are usually entered into the patient's treatment cards and the facility's register.

The study centers were: Faith Alive Foundation Hospital (FAF), Our Lady of Apostles (OLA), COCIN Hospital and Rehabilitation Centre (CHRC) Mangu, and Bingham University Teaching Hospital (BUTH), which are faith based hospitals. Plateau State Specialist 
Hospital (PSSH) is a tertiary health care institution owned by Plateau State Government. CHRC, FAF and OLA are secondary health care institutions, while BUTH is a tertiary health care institution.

\section{Ethics}

The Institutional Health Research Ethical Committee of the Jos University Teaching Hospital, Jos, Nigeria approved the protocol of this study to access the data used for the research and to use de-identified patient data for analysis.

\section{Data collection}

Data were collected from 10,156 TB facility registers and treatment cards of patients who accessed TB treatment from DOT treatment centers from 2001 to 2015 by the researcher and trained research assistants. Data were collected manually, using a pre-designed form before tranferring to the study database. Data collected included TB patient's demographic (sex, age, address, year of enrollment) and clinical characteristics (diagnosis, TB category, retreatment, sputum Acid Fast Bacilli-AFB analysis, period of defaulting), as well as their treatment outcomes. Socioeconomic data were not recorded at the facilities during the study period. Incomplete data especially those without recorded treatment outcomes were excluded from the study.

\section{Data analysis}

Data checking and coding was done in Microsoft Excel before exporting to STATA $^{\odot}$ version 11.0 (College Station Texas, USA) for analysis. Demographic and clinical characteristics of the TB patients were presented in proportions. Categorical variable proportions were compared using Chi-square test and where appropriate, Fisher's exact test was used. Bivariate analysis was used to determine patient and clinical characteristics factors associated with treatment outcomes. For the multivariate analysis, factors with $p$ values $\leq 0.2$ were included in the model, taking into account all the potential confounders. Missing values, which were determined to be missing at random were managed using complete case analysis.

\section{Definition of terms}

Treatment outcomes of TB patients in this study were classified as successful (cured or treatment completed) or unsuccessful (defaulted, treatment failure or died), as defined from the World Health Organization (WHO) and National TB and Leprosy Control Program (NTBLCP) guidelines [1, 5, 25, 26]. This study used successful and unsuccessful treatment outcomes as the outcome measure.

Cured refers to a pulmonary TB patient who was smear or culture positive at the beginning of treatment and is smear or culture negative upon completion of treatment [5].

Completed Treatment is a TB patient who completed treatment but without evidence (no laboratory test) at the end of treatment [25].

Successful treatment outcome: Cured and completed treatment together make up successful treatment outcomes which should increase towards $100 \%$ and reach at least $85 \%$ with good case management [5].

Unsuccessful Treatment outcome includes: defaulted/ lost to follow-up, treatment failure or died.

Treatment Failure is a PTB patient who was smear or culture positive at beginning of treatment and remains positive at month 5 or later during their most recent course of treatment [5].

Lost to follow-up is a TB patient who did not start treatment or whose treatment was interrupted for two consecutive months or more [5].

Defaulted is defined by the WHO as missing more than $20 \%$ of the prescribed doses during the treatment period i.e. a treatment interruption of two consecutive months or more after at least 1 month on treatment [26]. The definition of defaulters however can vary within national programs, for example, the Federal Ministry of Health in Nigeria, defined defaulting as not taking anti-TB medications consecutively for more than 2 days intensive phase and more than two consecutive weeks continuation phase [25].

Retreatment is a sputum AFB positive TB patient who had a one or more month extension of intensive phase due to sputum inconversion [25].

Relapse is a patient who was cured or completed treatment, but returned sputum positive or with clinical symptoms of TB (either a true relapse or a new episode of TB caused by reinfection) [5].

Died refers to a TB patient who died for any reason during the course of treatment [25].

\section{Results}

During the study period we utilized data from 10,156 TB patients who received treatment from five treatment centers. The mean age \pm SD was $35.5 \pm 15.5$. The proportion of males was more (58\%) than the females as seen in Table 1. Majority of the TB patients were in the productive age of 24-35 years of age (33.4\%) and were HIV positive (38.4\%). Patient enrollment increased from 22.0 to $39.6 \%$ over the 15 -year period, with the enrollment of HIV positive TB patients also increasing from 2.3 to $57.7 \%$. Mean time-outcome \pm SD was $5.4 \pm 3.0$ (time in months).

Majority of the patients were new (93.3\%) and had pulmonary TB (92.4\%). Most of the patients that returned after default, relapsed, developed multidrug resistance, or needed retreatment were HIV negative TB 
Table 1 Demographic Characteristics of TB Patients by HIV Status $(n=10,156)$

\begin{tabular}{|c|c|c|c|c|}
\hline Variable & $\begin{array}{l}\text { HIV Negative } \\
(n=3733) \text { Freq. (\%) }\end{array}$ & $\begin{array}{l}\text { HIV Positive } \\
(n=2968) \text { Freq. (\%) }\end{array}$ & $\begin{array}{l}\text { Unknown HIV Status } \\
(n=3455) \text { Freq. }(\%)\end{array}$ & Total Freq. (\%) \\
\hline \multicolumn{5}{|l|}{ Sex } \\
\hline Male & $2467(66.1)$ & $1343(45.2)$ & $2094(60.6)$ & $5904(58.1)$ \\
\hline Female & 1266 (33.9) & $1625(54.8)$ & $1361(39.4)$ & $4252(41.9)$ \\
\hline \multicolumn{5}{|l|}{ Age (Years) } \\
\hline 0-14 & $159(4.3)$ & $93(3.1)$ & $297(8.6)$ & $549(5.4)$ \\
\hline $15-24$ & $503(13.5)$ & $237(8.0)$ & $261(7.6)$ & $1001(9.9)$ \\
\hline $25-34$ & $1135(30.4)$ & $1069(36.0)$ & $599(17.3)$ & $2803(27.6)$ \\
\hline $35-44$ & $686(18.4)$ & $856(28.8)$ & $431(12.5)$ & $1973(19.4)$ \\
\hline $45-54$ & $489(13.1)$ & $364(12.3)$ & $238(6.9)$ & $1091(10.7)$ \\
\hline$>54$ & $583(15.6)$ & $163(5.5)$ & $230(6.7)$ & $976(9.6)$ \\
\hline Not Recorded & $178(4.8)$ & $186(6.3)$ & $1399(40.5)$ & $1763(17.4)$ \\
\hline \multicolumn{5}{|l|}{ Patient Residence } \\
\hline Jos North & $1393(37.3)$ & $1188(40.0)$ & $1992(57.7)$ & $4573(45.0)$ \\
\hline Jos South & $390(10.4)$ & $446(15.0)$ & $594(17.2)$ & $1430(14.1)$ \\
\hline Jos East & $139(3.7)$ & $127(4.3)$ & $194(5.6)$ & $460(4.5)$ \\
\hline Other LGAs in Plateau & $992(26.6)$ & $531(17.9)$ & $540(15.6)$ & $2063(20.3)$ \\
\hline \multicolumn{5}{|l|}{ Other States Outside } \\
\hline Plateau & $133(3.6)$ & $138(4.6)$ & $134(3.9)$ & $405(4.0)$ \\
\hline Not recorded & $686(18.4)$ & $538(18.1)$ & $1(0.0)$ & $1225(12.1)$ \\
\hline \multicolumn{5}{|l|}{ Year of Enrollment } \\
\hline $2001-2005$ & $0(0.0)$ & $67(2.3)$ & $2169(62.8)$ & $2236(22.0)$ \\
\hline 2006-2010 & $1531(41.0)$ & $1188(40.0)$ & $1179(34.1)$ & $3898(38.4)$ \\
\hline $2011-2015$ & 2202 (59.0) & 1713 (57.7) & 107 (3.1) & 4022 (39.6) \\
\hline
\end{tabular}

Freq. Frequency, LGAs Local Government Areas

Patients. Non-adherence/defaulting rate was $18.5 \%$, with majority of the patients, especially those with unknown HIV status defaulting at the end of intensive phase. The sputum conversion rate was $72.8 \%$ (Table 2). The patient enrollment in 2001 was 360 patients, which rose to a peak of 983 patients in 2013, but decreased to 721 in 2015 as shown in Fig. 1.

Treatment outcomes from DOT Facilities showed treatment success rate highest in OLA hospital (86.2\%) Non-adherence/defaulting rate was highest in Plateau State Specialist Hospital (26.4\%). Mortality rate was highest (10.5\%) in CHRC Mangu (Table 3).

TB patients with known HIV status had higher treatment success rates than those with unknown HIV status. Non-adherence/defaulting rate was highest (34.0\%) among TB patients with unknown HIV status and mortality was highest (11.2\%) among HIV positive TB patients (Table 4).

The trend of TB treatment outcomes in Fig. 2 showed a steady increase in treatment success rates over the years, with a peak of $83.8 \%$ in 2011 , but dropped to a low $64.4 \%$ in 2015 . A consequent reverse trend was seen in unsuccessful treatment, with a peak in 2002 (59.9\%) and $30.5 \%$ in 2015.

The factors significantly associated with treatment success from a univariate analysis were sex, age, year of enrollment, HIV status, TB category, retreatment and adherence. After adjusting for sex, age, year of enrollment and TB diagnosis in a multivariate analysis, having a known HIV status was more likely to be associated with treatment success than having an unknown HIV status $(p<0.001)$. Extrapulmonary TB patients were less likely to be associated with treatment success (95\% CI: 0.61-0.84, $p<0.001$ ) than pulmonary TB patients as shown in Table 5 .

\section{Discussion}

This study was conceptualized to assess and understand the factors associated with treatment outcomes in TB patients who received treatment at selected treatment facilities in Plateau State, North-central Nigeria, with more focus on the effect HIV has on the TB treatment outcomes. An overall treatment success rate of $67.4 \%$ was found and this was less than Plateau State's success rate of $72.7 \%$ [4] and global success rate of $82.0 \%$ [1]. A 
Table 2 Clinical characteristics of tuberculosis patients by HIV Status $(n=10,156)$

\begin{tabular}{|c|c|c|c|c|}
\hline Variable & $\begin{array}{l}\text { HIV Negative } \\
(n=3733) \text { Freq. }(\%)\end{array}$ & $\begin{array}{l}\text { HIV Positive } \\
(n=2968) \text { Freq. (\%) }\end{array}$ & $\begin{array}{l}\text { Unknown HIV Status } \\
(n=3455) \text { Freq. }(\%)\end{array}$ & Total Freq. (\%) \\
\hline \multicolumn{5}{|l|}{ TB Diagnosis } \\
\hline Pulmonary TB & 3311 (88.7) & $2818(94.9)$ & $3258(94.3)$ & 9387 (92.4) \\
\hline Extra-PTB & $422(11.3)$ & $150(5.1)$ & $197(5.7)$ & $769(7.6)$ \\
\hline TB Spine & $227(6.1)$ & $29(1.0)$ & $92(2.7)$ & $348(3.4)$ \\
\hline TB Adenitis & $39(1.0)$ & $22(0.7)$ & $19(0.5)$ & $80(0.8)$ \\
\hline TB Abdomen & 135 (3.6) & $91(3.1)$ & $61(1.8)$ & $287(2.8)$ \\
\hline Others $^{a}$ & $21(0.6)$ & $8(0.3)$ & $25(0.7)$ & $54(0.5)$ \\
\hline \multicolumn{5}{|l|}{ TB Category } \\
\hline New & $3405(91.2)$ & 2778 (93.6) & $3290(95.2)$ & $9473(93.3)$ \\
\hline RAD/TALF & $104(2.8)$ & $59(2.0)$ & $55(1.6)$ & $218(2.1)$ \\
\hline Relapse & $161(4.3)$ & $72(2.4)$ & $49(1.4)$ & $282(2.8)$ \\
\hline Trt. Failure & $11(0.3)$ & $7(0.2)$ & $1(0.0)$ & $19(0.2)$ \\
\hline Transfer-In & $52(1.4)$ & $52(1.8)$ & $60(1.7)$ & $164(1.6)$ \\
\hline \multicolumn{5}{|l|}{ Needing Retreatment } \\
\hline No & $3290(88.1)$ & $2704(91.1)$ & $2979(86.2)$ & $8973(88.4)$ \\
\hline Yes & $282(7.6)$ & $136(4.6)$ & $104(3.0)$ & $522(5.1)$ \\
\hline Indeterminate ${ }^{b}$ & $161(4.3)$ & $128(4.3)$ & $372(10.8)$ & $661(6.5)$ \\
\hline \multicolumn{5}{|l|}{ Sputum AFB on Diagnosis } \\
\hline Sputum Negative & $2355(63.1)$ & $2398(80.8)$ & $2480(71.8)$ & $7233(71.2)$ \\
\hline Sputum AFB Positive & $1378(36.9)$ & $570(19.2)$ & $975(28.2)$ & $2923(28.8)$ \\
\hline \multicolumn{5}{|c|}{ Sputum AFB After Intensive Phase } \\
\hline Sputum Negative & $3510(94.0)$ & $2806(94.5)$ & $3044(88.1)$ & $9360(92.2)$ \\
\hline Sputum AFB Positive & $39(1.0)$ & $18(0.6)$ & $12(0.3)$ & $69(0.7)$ \\
\hline Indeterminate ${ }^{b}$ & $184(4.9)$ & $144(4.9)$ & $398(11.5)$ & $726(7.1)$ \\
\hline \multicolumn{5}{|c|}{ Defaulting Period $(n=1874)$} \\
\hline During Intensive Phase & $97(2.6)$ & $65(2.2)$ & $271(7.8)$ & $433(4.3)$ \\
\hline End of Intensive Phase & $190(5.1)$ & $191(6.4)$ & $559(16.2)$ & $940(9.3)$ \\
\hline Continuation Phase & $96(2.6)$ & $62(2.1)$ & $343(9.9)$ & $501(4.9)$ \\
\hline \multicolumn{5}{|l|}{ Binary Outcome } \\
\hline Unsuccessful & $919(24.6)$ & $781(26.3)$ & $1599(46.3)$ & $3299(32.5)$ \\
\hline Successful & $2814(75.4)$ & $2187(73.7)$ & $1855(53.7)$ & $6856(67.5)$ \\
\hline
\end{tabular}

${ }^{a}=$ Disseminated TB, Miliary TB, Ovarian TB, Pleural TB, Skin TB, Heart TB

${ }^{b}$ Indeterminate due to lost to follow-up or death during intensive phase of treatment RAD Return after Default, TALF Treatment after lost to follow up,

Trt Treatment

drop in the overall treatment success rate from $83.8 \%$ in 2011 to $64.4 \%$ in 2015 was also observed. Known HIV status was significantly associated with successful treatment outcomes, while extrapulmonary TB was less likely to be associated with treatment success. The association between positive HIV status and treatment success could be attributed to better medication adherence given that most HIV infected patients in the treatment facilities typically receive intensive adherence counseling for their antiretroviral medications including the need to be adherent to TB therapy.
Tuberculosis disease was found more in males than females as similarly observed in other studies [27, 28]. The possible reasons given were; women experiencing barriers to service access, longer clinical delays in diagnosis or producing sputum of poor quality than men [29]. A community based intervention study however reported significantly more women diagnosed with $\mathrm{TB}$ at community level than in the health facilities because the interventions reduced barriers to services with poor women who had previously faced difficulties travelling to health centres particularly benefitting [29]. Females were more 


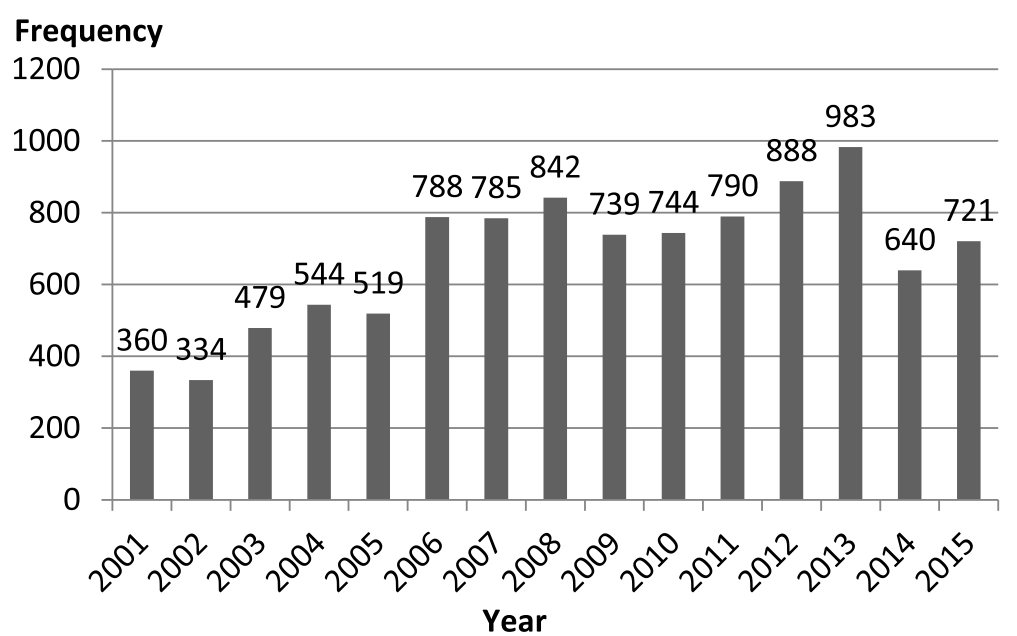

Fig. 1 Tuberculosis Patient's Enrollment Trend $(n=10,156)$

likely to have successful treatment outcomes than males as seen in Table 5 probably due to higher risk behaviours (alcohol, substance and tobacco abuse) observed in males than females $[4,27]$.

TB was found more in the productive age group (sexually active group), particularly among HIV positive TB patients as similarly observed in other studies and consistent with global epidemiological findings [21, 30-34]. Majority of the patients were from Jos North Local Government Area of Plateau State, where most of the data was collected. These centers were chosen because they had records of TB patients from the inception of the Directly Observed Treatment progam for TB in Plateau State in 2001. They also constitute about more than half of the population of TB patients in Plateau state.

CHRC Mangu, a rural DOT secondary facility had the lowest failure rate $(0.2 \%)$ and defaulting rate $(2.9 \%)$ but recorded the highest transfer-out (9.1\%) and mortality rates $(10.5 \%)$ than the urban DOT facilities. Training of health staff and treatment supporters should be encouraged so the community is more aware and educated on tuberculosis disease in order to increase case detection and decrease late reporting when the disease is advanced. Medication education and adherence counseling would further reduce treatment failure and defaulting rates. CHRC Mangu was receiving support from the Netherlands TB and Leprosy Relief. This drew a lot of patients from both Mangu and other Local Government Areas around the state because it was an active TB diagnostic and treatment centre. The Netherlands support was however withdrawn in 2016, now making Mangu more of a dignostic and less of a treatment centre. Therefore patients diagnosed with TB in Mangu were referred to DOT centers closest to their residence for treatment; the probable reason behind the high transferout rates.

\section{Patient enrollment and treatment outcomes}

The number of TB patients that accessed treatment increased from 360 patients in 2001 to 983 in 2013, especially among HIV positive TB patients. This could likely be due to the increase in prevalence (from $2.2 \%$ in 1991 to $25 \%$ in 2010) of HIV disease among TB patients [34] and improved documention processes. DOT expansion

Table 3 Treatment Outcomes from DOT Facilities $(n=10,156)$

\begin{tabular}{|c|c|c|c|c|c|c|c|}
\hline Hosp. & $\begin{array}{l}\text { Successful } \\
\text { Treatment Freq. (\%) }\end{array}$ & Defaulted Freq. (\%) & $\begin{array}{l}\text { Treatment } \\
\text { Failure Freq. (\% }\end{array}$ & Died Freq. (\%) & $\begin{array}{l}\text { Discontinued } \\
\text { Treatment Freq. (\%) }\end{array}$ & $\begin{array}{l}\text { TransferOut } \\
\text { Freq. (\%) }\end{array}$ & Total \\
\hline OLA & 1189 (86.2) & $58(4.2)$ & $15(1.1)$ & $79(5.7)$ & $2(0.2)$ & $36(2.6)$ & 1379 (13.6) \\
\hline FAF & $1126(85.6)$ & $81(6.2)$ & $4(0.3)$ & $84(6.4)$ & $0(0.0)$ & $20(1.5)$ & $1315(12.9)$ \\
\hline $\mathrm{CHRC}$ & $1467(77.3)$ & $55(2.9)$ & $4(0.2)$ & 199 (10.5) & $1(0.1)$ & $172(9.1)$ & $1898(18.7)$ \\
\hline PSSH & $1872(58.2)$ & $848(26.4)$ & $17(0.5)$ & $236(7.3)$ & $11(0.3)$ & $233(7.2)$ & $3217(31.7)$ \\
\hline BUTH & $1190(50.7)$ & $846(36.1)$ & $11(0.5)$ & $161(6.9)$ & $4(0.2)$ & $135(5.8)$ & $2347(23.1)$ \\
\hline Total & $6844(67.4)$ & $1888(18.6)$ & $51(0.5)$ & $759(7.5)$ & $18(0.2)$ & $596(5.9)$ & $10,156(100.0)$ \\
\hline
\end{tabular}

Hosp. Hospital, Freq. Frequency, OLA Our Lady of Apostles Hospital, FAF Faith Alive Foundation Hospital, CHRC COCIN Hospital and Rehabilitation Centre Mangu, BUTH Bingham University Teaching Hospital, PSSH Plateau State Specialist Hospital 
Table 4 Distribution of Tuberculosis Treatment Outcomes by HIV Status $(n=10,156)$

\begin{tabular}{lllll}
\hline Treatment Outcome & HIV Negative Freq. (\%) & HIV Positive Freq. (\%) & Unknown HIV Status Freq. (\%) & Total Freq. (\%) \\
\hline Transfer-Out & $227(38.2)$ & $117(19.7)$ & $251(42.2)$ & $595(5.9)$ \\
Cured & $1037(50.8)$ & $488(23.9)$ & $514(25.2)$ & $1341(27.8)$ \\
Treatment Completed & $1777(36.9)$ & $1699(35.3)$ & $1856(27.1)$ & $4817(47.4)$ \\
Treatment Success & $2814(41.0)$ & $2187(31.9)$ & $1173(62.6)$ & $9857(67.5)$ \\
Defaulted & $383(20.4)$ & $318(17.0)$ & $9(17.0)$ & $1874(18.5)$ \\
Treatment Failure & $33(62.3)$ & $11(20.8)$ & $162(21.3)$ & $53(0.5)$ \\
Died & $266(35.0)$ & $331(43.6)$ & $4(22.2)$ & $189(7.5)$ \\
Discontinued Trt. & $10(55.6)$ & $4(22.2)$ & $3455(34.0)$ & $10.2)$ \\
Total & $3733(36.8)$ & $2968(29.2)$ & & $10,156(100.0)$ \\
\hline
\end{tabular}

Trt Treatment, Freq. Frequency

resulting to an increase in DOT facilities from 5 in 2001 to 290 in 2019 may have also increased the case detection rate $[4,30,31]$. The number of $\mathrm{TB}$ patients that accessed TB treatment in the DOT centres however dropped between 2014 and 2015, probably for lack of training and update on appropriate management of TB. The trend in treatment outcomes followed a similar pattern where the treatment success increased steadily from 2001 (52.2\%) to a peak in 2011 (83.8\%) but dropped to $64.4 \%$ in 2015 . The increase in treatment failure and mortality rate observed from the 5 -year interval of treatment outcome distribution in Table 6 may be due to the high non-adherence rate observed. The Nigerian National $\mathrm{TB}$ and Leprosy control programme is presently training and re-training TB DOT officers to improve TB health care services.

There was an increase in non-adherence/defaulting rate from $30.6 \%$ in 2001 to $54.2 \%$ in 2002 , which was the highest defaulting rate observed over the years. This may have been as a result of the strict compliance of DOT, where TB patients came everyday for $2-3$ months (initial phase of treatment) with the DOT officers observing them take their medicines. This may have contributed to the high defaulting rate since patients could potentially get tired or experience some barrier to accessing the facilities for DOT. Some of these barriers include transportation cost, financial constraints and lack of social support system. Indeed, previous reports have offered recommendations to modify the DOT system of accessing TB treatment $[35,36]$. This probably led to the susequent decrease in defaulting rate as contact tracing, community DOT and decrease in number of visits to the DOT center from daily to weekly is currently being practiced.

\section{Factors associated with treatment outcomes}

Having a known HIV status was associated with treatment success as similarly observed in other studies [37, 38]. Patients on both anti-retroviral and anti-TB medicines were more likely to adhere because they received

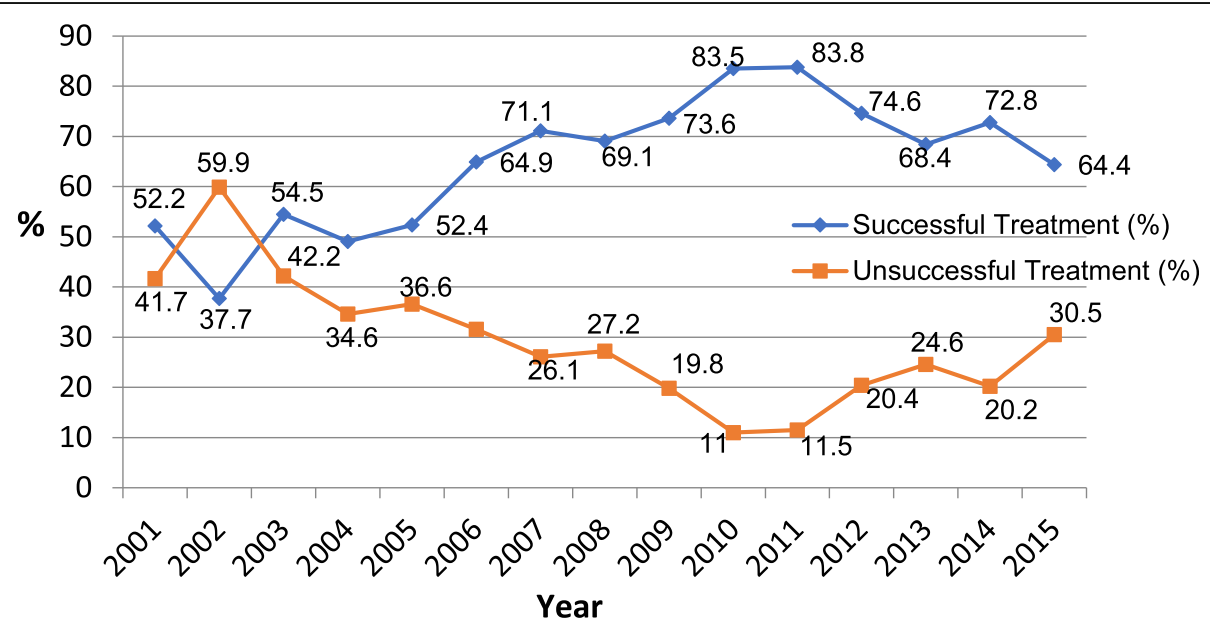

Fig. 2 Trend of Tuberculosis Treatment Outcomes $(n=10,156)$ 
Table $\mathbf{5}$ Factors associated with tuberculosis treatment success

\begin{tabular}{|c|c|c|c|c|c|c|}
\hline \multirow[t]{2}{*}{ Variable } & \multicolumn{2}{|c|}{ Treatment Outcome rate } & \multirow[t]{2}{*}{ COR (95\% Cl) } & \multirow{2}{*}{$\begin{array}{l}p \\
\text { (COR) }\end{array}$} & \multirow[t]{2}{*}{ AOR $(95 \% \mathrm{Cl})$} & \multirow{2}{*}{$\begin{array}{l}p \\
(\mathrm{AOR})\end{array}$} \\
\hline & $\begin{array}{l}\text { Unsuccessful } \\
\boldsymbol{n}=3299 \\
\text { Freq. (\%) }\end{array}$ & $\begin{array}{l}\text { Successful } \\
\boldsymbol{n}=6856 \\
\text { Freq. (\%) }\end{array}$ & & & & \\
\hline \multicolumn{7}{|l|}{ Gender } \\
\hline Male & $1998(60.6)$ & $3906(57.0)$ & Reference & & Reference & \\
\hline Female & $1301(39.4)$ & $2950(43.0)$ & $1.160(1.066-1.262)$ & 0.010 & $1.161(1.063-1.269)$ & 0.001 \\
\hline \multicolumn{7}{|l|}{ Age } \\
\hline Not Recorded & $877(26.6)$ & $886(12.9)$ & Reference & & Reference & \\
\hline$<15$ years & $243(7.4)$ & $353(5.1)$ & $1.438(1.191-1.736)$ & 0.001 & $1.289(1.061-1.567)$ & 0.011 \\
\hline$>15$ years & $2179(66.1)$ & 5617 (81.9) & $2.552(2.296-2.836)$ & 0.001 & $1.819(1.609-2.057)$ & 0.001 \\
\hline \multicolumn{7}{|l|}{ Enrollment Year } \\
\hline $2001-2005$ & $1121(34.0)$ & $1114(16.2)$ & Reference & & Reference & \\
\hline $2006-2010$ & $1082(32.8)$ & $2816(41.1)$ & 2.619 (2.349-2.919) & 0.001 & $1.646(1.435-1.889)$ & 0.001 \\
\hline 2011-2015 & $1096(33.2)$ & $2926(42.7)$ & $2.686(2.411-2.993)$ & 0.001 & $1.255(1.060-1.486)$ & 0.009 \\
\hline \multicolumn{7}{|l|}{ TB Diagnosis } \\
\hline РTB & 3025 (91.7) & $6361(92.8)$ & Reference & & Reference & \\
\hline EPTB & $274(8.3)$ & $495(7.2)$ & $0.859(0.737-1.002)$ & 0.053 & $0.717(0.611-0.841)$ & $<0.001$ \\
\hline \multicolumn{7}{|l|}{ HIV Status } \\
\hline Negative & $919(27.9)$ & $2814(41.0)$ & $2.639(2.388-2.917)$ & 0.001 & $1.848(1.593-2.143)$ & $<0.001$ \\
\hline Positive & $781(23.7)$ & 2187 (31.9) & $2.414(2.172-2.683)$ & 0.001 & $1.621(1.394-1.885)$ & $<0.001$ \\
\hline Unknown & $1599(48.5)$ & $1855(27.1)$ & Reference & & Reference & \\
\hline \multicolumn{7}{|l|}{ TB Category } \\
\hline Transfer-In & $40(1.2)$ & $124(1.8)$ & Reference & & & \\
\hline New & $3063(92.8)$ & 6409 (93.5) & $0.675(0.471-0.966)$ & 0.032 & & \\
\hline RAD/TALF & $86(2.6)$ & $132(1.9)$ & $0.495(0.316-0.775)$ & 0.002 & & \\
\hline Relapse & $99(3.0)$ & $183(2.7)$ & $0.596(0.387-0.919)$ & 0.019 & & \\
\hline Trt. Failure & $11(0.3)$ & $8(0.1)$ & $0.235(0.088-0.624)$ & 0.004 & & \\
\hline \multicolumn{7}{|c|}{ Needing Retreatment } \\
\hline No & $2459(74.5)$ & $6513(95.0)$ & Reference & & & \\
\hline Yes & $180(5.5)$ & $342(5.0)$ & $0.717(0.595-0.864)$ & 0.001 & & \\
\hline Indeterminate+ & $660(20.0)$ & $1(0.0)$ & $0.001(0.000-0.004)$ & 0.001 & & \\
\hline \multicolumn{7}{|l|}{ Adherent } \\
\hline No & $3296(99.9)$ & $15(0.2)$ & $\begin{array}{l}0.001(0.000> \\
1.0 \mathrm{E} 12)\end{array}$ & 0.999 & & \\
\hline Yes & $3(0.1)$ & 6842 (99.8) & Reference & & & \\
\hline
\end{tabular}

COR Crude Odds Ratio, AOR Adjusted Odds Ratio, Trt Treatment, PTB Pulmonary TB, EPTB Extrapulmonary TB, RAD Return after Default, TALF Treatment after lost to follow up, + Indeterminate due to lost to follow-up or death during intensive phase of treatment

more adherence counseling than those taking only anti-TB medicines [37]. Socioeconomic characteristics, individual behaviour and health care worker were other factors reported to be associated with nonadherence across developing countries [38]. However, socioeconomic factors were not determined in this study due to unavailability of the records. TB patients with a history of defaulting/non-adherence were less likely to have successful treatment outcomes, consistent with findings from a previous study done in Plateau state [4] and other studies [30, 33]. A strengthening of adherence counseling is encouraged so that factors responsible can be identified and resolved. This is important because non-adherence and regular treatment interruptions can lead to the development of resistant $\mathrm{TB}$, treatment failure, relapse, longer infections or even death [30] - a finding observed in this study from the time trend of treatment outcomes in Table 6, and similarly reported by WHO that Nigeria is among the 14 countries with overlap high burden of $\mathrm{TB}, \mathrm{TB} / \mathrm{HIV}$ and multidrug resistantTB [1]. A study of the pattern of treatment outcomes over the years done in this study can also be carried out to identify specific areas in TB management that 
Table 6 Distribution of tuberculosis treatment outcomes by year of enrollment $(n=10,156)$

\begin{tabular}{lllll}
\hline Treatment Outcome & $2001-2005$ & $2006-2010$ & $2011-2015$ & Total Freq. (\%) \\
\hline Transfer-Out & $191(32.1)$ & $171(28.7)$ & $233(39.2)$ & $595(5.9)$ \\
Treatment Success & $1115(16.3)$ & $2816(41.1)$ & $2926(42.7)$ & $6857(67.5)$ \\
Defaulted & $792(42.3)$ & $724(38.6)$ & $358(19.1)$ & $1874(18.5)$ \\
Treatment Failure & $6(11.3)$ & $22(41.5)$ & $25(47.2)$ & $53(0.5)$ \\
Died & $128(16.9)$ & $158(20.8)$ & $473(62.3)$ & $7(38.9)$ \\
Treatment Discontinued & $4(22.2)$ & $7(38.9)$ & $4022(39.6)$ & $18(0.2)$ \\
Total & $2236(22.0)$ & $3898(38.4)$ & & 10,156 \\
\hline
\end{tabular}

require intervention in order to improve outcomes and health services.

Having a known HIV status was more likely to be associated with TB treatment success. A possible explanation for this finding is that the TB patients initially received voluntary counseling and testing, then those with $\mathrm{TB} / \mathrm{HIV}$ co-infection were likely to have received more/ reinforced adherence counseling from trained adherence counselors prior to commencement of therapy, including adherence to TB therapy. As with HIV treatment, TB therapy also requires high (>90\%) adherence to facilitate cure [39]. Thus, they may be more aware of the consequences of non-adherence in TB/HIV co-infection. HIV negative patients had higher odds of treatment success than HIV positive patients, consistent with findings from Central Ethiopia, Abuja-Nigeria and Abakaliki-Nigeria respectively [30, 34, 40], where HIV positive TB patients were significantly associated with poor $\mathrm{TB}$ treatment outcomes due to malabsorption of anti-TB medicines, high pill burden and poor knowledge about the diseases.

HIV negative TB patients had lower mortality rates than HIV positive TB patients, similar to studies reported in other states in Nigeria [34, 40], and other countries [41-43]. Possible reasons given were: TB treatment failure or complication of HIV disease [34], late diagnosis of HIV in TB patients [40], unavailability/inaccessibility of anti-retrovirals-ARVs [44], immunosuppression [45], lack of treatment supporters [46], and other co-morbidities such as cardiovascular diseases and diabetes mellitus [42-45] in HIV positive TB patients. If ARVs are procured, supplied and dispensed without disruption, it may go a long way to reduce the high mortality rate in Nigeria [2]. Extra-pulmonary TB was less likely associated with treatment success than pulmonary TB patients. This was explained in previous studies that extra- pulmonary TB may be associated with immunosuppression more than pulmonary TB [47-49].

This study was limited by missing variables not recorded in the $\mathrm{TB}$ registers such as education, occupation and income, making it difficult to estimate the socioeconomic status of TB patients and how it may have influenced treatment outcomes in the analysis. Also, we treated treatment outcome as binary (successful versus unsuccessful) in our logistic regression models mainly because there were small numbers in the unsuccessful treatment outcome category. We acknowledge that this simplistic categorization may have biased or obscured the effect of the association on the outcomes reported. However, this study was able to identify factors associated with TB treatment success in the selected DOTs facilities, which may help the TB programme in the state and other areas with a high burden of TB during planning and implementation of interventions to improve treatment outcomes.

\section{Conclusions}

In summary, findings from this research showed that determination of HIV status for TB patients was associated with treatment success. HIV negative patients had higher odds of treatment success than HIV positive patients. Extra-pulmonary TB was less likely associated with TB treatment success. TB treatment outcomes from five DOT facilities were evaluated to show a decrease in tuberculosis treatment success rates from a fifteen-year retrospective study. Appropriate interventions that would strengthen the treatment supporter and health system through medication education and adherence counseling, as well as increased education on voluntary counseling and testing of HIV among TB patients is advocated. Similar studies can be carried out in other DOT facilities to identify factors associated with treatment outcomes so that appropriate facility-specific intervention(s) can be designed and implemented.

\footnotetext{
Abbreviations

TB: Tuberculosis; MDR-TB: Multidrug Resistant-Tuberculosis; AFB: Acid Fast Bacilli; NTBLCP: National Tuberculosis and Leprosy Control Program; WHO: World Health Organization; PTB: Pulmonary Tuberculosis;

TALF: Treatment after lost to follow up; RAD: Return after Default; DOT: Directly Observed Therapy; OLA: Our Lady of Apostles Hospital; FAF: Faith Alive Foundation Hospital; CHRC: COCIN Hospital and Rehabilitation Centre Mangu; BUTH: Bingham University Teaching Hospital; PSSH: Plateau State Specialist Hospital
} 


\section{Acknowledgements}

The support of Joshua Dung in data collection is highly appreciated. The contribution of Dr. Adamu Onu and Dr. Tolu Afolaranmi in data analysis is acknowledged.

\section{Authors' contributions}

CS and PO conceptualized the research idea, CS designed the study, JM analyzed most of the data, MD, JA and $\mathrm{LI}$ read and revised the manuscript. CS wrote the first draft of the manuscript and all co-authors read and approved the final version.

\section{Funding}

The design of the study, collection and analysis of the data was funded by the Africa Centre of Excellence in Phytomedicine Research and Development (ACEPRD) with grant award number 126974 from the World Bank. The analysis and interpretation of data, the manuscript writing and publication charge was funded by the Fogarty International Center of the National Institutes of Health under Award Number D43TW010130. The content is solely the responsibility of the authors and does not necessarily represent the official views of the National Institutes of Health.

\section{Availability of data and materials}

The datasets generated and analyzed during the current study are available from the corresonding author on reasonable request.

\section{Ethics approval and consent to participate}

The Institutional Health Research Ethical Committee of the Jos University Teaching Hospital, Jos, Nigeria (reference number: JUTH/DCS/ADM/127/XIX/ 6058) approved the protocol of this study and granted permission to access the data used for this research.

\section{Consent for publication}

Not Applicable.

\section{Competing interests}

The authors declare that they have no competing interests.

\section{Author details}

'Department of Clinical Pharmacy and Pharmacy Practice, Faculty of Pharmaceutical Sciences, University of Jos, Plateau State, Jos, Nigeria. ${ }^{2}$ Department of Pharmaceutical Chemistry, Faculty of Pharmaceutical Sciences, University of Jos, Plateau State, Jos, Nigeria. ${ }^{3}$ Department of Obstetrics and Gynaecology, Faculty of Medical Sciences, University of Jos, Plateau State, Jos, Nigeria. ${ }^{4}$ Department of Public Health, Ministry of Health, Plateau State, Jos, Nigeria. ${ }^{5}$ Department of Pharmacology, Faculty of Pharmaceutical Sciences, University of Jos, Plateau State, Jos, Nigeria.

\section{Received: 4 July 2019 Accepted: 23 July 2020}

\section{Published online: 11 August 2020}

\section{References}

1. World Health Organization-WHO. Global Tuberculosis Report. (2018). https:// apps.who.int/iris/bitstream/handle/10665/274453/9789241565646-eng.pdf. Accessed 1 Mar 2019.

2. Reid MJA, Arinaminpathy N, Bloom A, Boehme C, Chaisson R, Chin DP, et al. Building a tuberculosis-free world: the lancet commission on tuberculosis. Lancet. 2019:7-10. https://doi.org/10.1016/s0140-6736(19)30433-7 Accessed 16 Oct 2019.

3. World Health Organization-WHO. Global Tuberculosis Report. (2015). www. who.int. Accessed 3 Mar 2017.

4. Ibrahim LM, Hadejia IS, Nguku P, Lakda GM, Ogiri S, Patrobas P. Factors associated with outcomes of treatment among pulmonary tuberculosis patients in Plateau State, Nigeria. J US China Med Sci. 2011;12(2015):172-9. https://doi.org/10.17265/1548-6648/2015.04.005 Accessed 29 May 2020.

5. Federal Ministry of Health-FMOH. National tuberculosis, Leprosy and Buruli ulcer management and control guidelines. 6th ed. Abuja: NTBLCP; 2015.

6. World Health Organization-WHO. Tuberculosis. (2018). https://www.who.int/ news-room/fact-sheets/detail/tuberculosis. Accessed 16 Sept 2019.

7. Bam TS, Gunneberg C, Bam DS, Alberg O, Kasland O, Shiyalap K, et al. Factors affecting patient adherence to DOTs in urban Kathmandu, Nepal. Int J Tuberc Lung Dis. 2006;10(3):270-6 Accessed 20 June 2010.
8. Bello SI, Itiola O. Drug adherence amongst tuberculosis patients in the University of Ilorin Teaching Hospital, llorin. Nigeria Afr J Pharmacy Pharm. 2010;4(3):109-14 Accessed 13 Mar 2012.

9. Erhabor GE, Aghanwa HS, Yusuph M, Adebayo RA, Arogundade FA, Amidiora O. Factors influencing compliance in patients with tuberculosis on directly observed therapy at Ile-Ife, Nigeria. East Afr Med J. 2000;77(5):235-9 Accessed 20 June 2010.

10. Kaona FAD, Tuba M, Siziya S, Sikaona L. An assessment of factors contributing to treatment adherence and knowledge of TB transmission among patients on TB treatment. BMC Public Health. 2004;4(68) Accessed 20 June 2010.

11. Munro SA, Lewin SA, Smith HJ, Engel ME, Fretheim A, Volmink J. Patient adherence to tuberculosis treatment: a systematic review of qualitative research. PLoS Med. 2007:4(7):238.

12. Sariem CN, Gyang SS, Tayo F, Auta A, Omale S, Ndukwe HC. Factors influencing tuberculosis medication adherence in a tertiary health institution in Nigeria. West Afr J Pharm. 2013;24(2):66-75.

13. Sariem CN, Nanlir ZS, Banwat SB, Dapar MP. Factors influencing tuberculosis medication adherence: a cognitive intervention in a resource limited setting. World J Pharm Sci. 2015;3(9):1912-20.

14. Roter DL, Hall A, Merisca R, Nordstrom B, Cretin D, Svarstad B. Effectiveness of interventions to improve patient compliance: a meta-analysis. Med Care. 1998:36:1138-61.

15. Haynes RB, McDonald H, Garg AX, Montague P. Interventions for helping patients to follow prescriptions for medications. Cochrane Database Syst Rev. 2002;2:CD000011. https://doi.org/10.1002/14651858.CD000011.

16. Borgdroff MW, Floyd K, Broekmans JF. Intervention to reduce tuberculosis mortality and transmission in low- and middle-income countries. Bulletin WHO. 2002;80:217-27.

17. Munro $\mathrm{S}$. Theoretical models to support long-term medication adherence in TB and HIV. 3rd international conference on ARV treatment adherence. South African Medical Research Council: NJ, USA; 2008.

18. Chisholm-Burns MA, Spivey CA. Pharmacoadherence: a new term for a significant problem. Am J Health-System Pharm. 2008;65(7):661-7.

19. Arentz M, Narita M, Sangaré L, Kah JF, Low D, Mandaliya K, Walson JL. Impact of smear microscopy results and observed therapy on tuberculosis treatment in Mombasa, Kenya. Int J Tuberc lung Dis. 2011;15(12):1656-63. https://doi.org/10.5588/ijtld.10.0625.

20. Horne R, Weinman J, Barber N, Elliot R, Morgan M. Concordance, adherence and compliance in medicine taking. (2005). www.epha.org/IMG/pdf/Rob_ Horne_EP_handouts.pdf. Accessed 7 July 2010.

21. Dim CC, Dim NR. Trends of tuberculosis prevalence and treatment outcome in an under-resourced setting: the case of Enugu state, South East Nigeria. NMJ. 2014;54(6):392-7.

22. Ukwaja KN, Alobu I, Ifebunandu NA, Osakwe C, Igwenyi C. Trend in case detection rate for all tuberculosis cases notified in Ebonyi, Southeastern Nigeria during 1999-2009. Pan Afr Med J. 2013;16(11) Accessed 13 July 2017.

23. Fatiregun AA, Ojo AS, Bambgboye AE. Treatment outcomes amomg pulmonary tuberculosis patients at treatment centres in Ibadan, Nigeria. Annals Afr Med. 2009:8(2):100-4 Accessed 13 July 2017.

24. NPC. Abuja, Nigeria: National Population Commission. 2017. http://www. population.gov.ng/index.php/state-population. Accessed 13 July 2017.

25. Federal Ministry of Health-FMOH. National Tuberculosis and Leprosy Control Program. Abuja: (NTBLCP) Workers Manual Final Draft; 2008.

26. World Health Organization-WHO. Adherence to long term therapies: evidence for action. (2003). http://whqlibdoc.who.intpublications2003 9241545992.pdf. Accessed 1 Mar 2016.

27. Johansson E, Long NH, Diwan VK, Winkvist A. Gender and tuberculosis control. Health Policy. 2000;52(1):33-51 Accessed 13 July 2017.

28. Weiss MG, Sommerfeld J, Uplekar MW. Social and cultural dimensions of gender and tuberculosis [editorial] [special section on gender and TB]. Int J Tuberc lung Dis. 2008;12(7):829-30 Accessed 27 July 2017.

29. Yassin MA, Datiko DG, Tulloch O, Markos P, Aschalew M, Shargie EB, et al. Innovative community-based approaches doubled tuberculosis case notification and improve treatment outcome in Southern Ethiopia. PLoS One. 2013;8(5):e63174.

30. Hamusse SD, Demissie M, Teshome D, Lindtjørn B. Fifteen-year trend in treatment outcomes among patients with pulmonary smear-positive tuberculosis and its determinants in Arsi zone, Central Ethiopia. Glob Health Action. 2014;7(25382):10. 
31. Dangisso MH, Datiko DG, Lindtjørn B. Trends of tuberculosis case notification and treatment outcomes in the Sidama Zone, Southern Ethiopia: ten-year retrospective trend analysis in urban-rural settings. PLoS One. 2014:9(12):e114225.

32. Hamid-Salim MA, Declercq E, Van-Deun A, Saki KAR. Gender differences in tuberculosis: a prevalence survey done in Bangladesh. Int I Tuberc lung Dis. 2004;8:952-7.

33. Shargie EB, Lindtjørn B. DOTS improves treatment outcomes and service coverage for tuberculosis in South Ethiopia: a retrospective trend analysis. BMC Public Health. 2005;5:62.

34. Ofoegbu OS, Odume BB. Treatment outcome of tuberculosis patients at National Hospital Abuja Nigeria: a five year retrospective study. South Afri Fam Pract. 2015;57(1):50-6.

35. Sariem CN, Ndukwe HC, Dayom WD. Assessing the effectiveness of directly observed therapy short-course (DOTs) for tuberculosis in a Nigerian hospital. J Pharm Biores. 2012;9(2):116-21.

36. MacLehose HG. Improving practice using systematic reviews: a series about evidence-based practice. Afri Health. 2002;7:11-7.

37. Amuha MG, Kutyabami P, Kitutu FE, Odoi-Adome R, Kalyango JN. Nonadherence to anti-TB drugs among TB/HIV co-infected patients in Mbarara hospital Uganda: prevalence and associated factors. Afr Health Sci. 2009; 9(Suppl 1):S8-S15 Accessed 11 May 2020.

38. Tola HH, Tol A, Shojaeizadeh D, Garmaroudi G. Tuberculosis treatment nonadherence and lost to follow up among TB patients with or without HIV in developing countries: a systematic review. Iran J Public Health. 2015;44(1):111 Accessed 11 May 2020.

39. Awofeso N. Anti-tuberculosis medication side-effects constitute major factor for poor adherence to tuberculosis treatment. Bull World Health Organ. 2008;86(3):161-240.

40. Ifebunandu NA, Ukwaja KN, Obi SN. Treatment outcome of HIV-associated tuberculosis in a resource-poor setting. Trop Doct. 2012;42:74-6. https://doi. org/10.1258/td.2011.110421 Accessed 12 Oct 2019.

41. Hargreaves NJ, Kadzakumanja O, Whitty CJ, Salaniponi FM, Harries AD, Squire SB. 'Smear-negative' pulmonary tuberculosis in a DOTS programme: poor outcomes in an area of high HIV seroprevalence. Int J Tuberc Lung Dis. 2001;5:847-54.

42. Lienhardt C, Manneh K, Bonchier V, Lahai G, Millian PJ, McAdam KP. Factors determining the outcome of treatment of adult smear positive tuberculosis cases in the Gambia. Int J Tuberc Lung Dis. 1998;2:712-8.

43. Marks SM, Magee E, Robison V. Patients diagnosed with tuberculosis at death or who died during therapy: association with the human immunodeficiency virus. Int J Tuberc Lung Dis. 2011;15(4):465-70.

44. King L, Munsiff SS, Ahuja SD. Achieving international targets for tuberculosis treatment success among HIV-positive patients in New York City. Int J Tuberc Lung Dis. 2010;14(12):1613-20.

45. Waitt CJ, Squire SB. A systematic review of risk factors for death in adults during and after tuberculosis treatment. Int J Tuberc Lung Dis. 2011;15(7): 871-85.

46. Burton NT, Forson A, Lurie MN, et al. Factors associated with mortality and default among patients with tuberculosis attending a teaching hospital clinic in Accra, Ghana. Trans R Soc Trop Med Hyg. 2011;105(12):675-82. https://doi.org/10.1016/j.trstmh.2011.07.017 Accessed 16 Oct 2019.

47. Pang Y, An J, Shu W, Huo F, Chu N, Gao M, et al. Epidemiology of Extrapulmonary tuberculosis among inpatients, China, 2008-2017. Emerg Infect Dis. 2019;25(3):457-64. https://doi.org/10.3201/eid2503.180572 Accessed 16 Oct 2019

48. Sterling TR, Dorman SE, Chaisson RE, Ding L, Hackman J, Moore K, Holland SM. Human immunodeficiency virus-seronegative adults with extrapulmonary tuberculosis have abnormal innate immune responses. Clin Infect Dis. 2001;33:976-82. https://doi.org/10.1086/322670 Accessed 15 Oct 2019.

49. Jones BE, Young SM, Antoniskis D, Davidson PT, Kramer F, Barnes PF. Relationship of the manifestations of tuberculosis to CD4 cell counts in patients with human immunodeficiency virus infection. Am Rev Respir Dis. 1993;148:1292-7. https://doi.org/10.1164/ajrccm/148.5.1292.

\section{Publisher's Note}

Springer Nature remains neutral with regard to jurisdictional claims in published maps and institutional affiliations.

Ready to submit your research? Choose BMC and benefit from:

- fast, convenient online submission

- thorough peer review by experienced researchers in your field

- rapid publication on acceptance

- support for research data, including large and complex data types

- gold Open Access which fosters wider collaboration and increased citations

- maximum visibility for your research: over $100 \mathrm{M}$ website views per year

At $\mathrm{BMC}$, research is always in progress.

Learn more biomedcentral.com/submissions 